\title{
Design Method for Proportion of Cement- Foamed Asphalt Cold Recycled Mixture
}

\author{
Junxiao $\mathrm{Li}^{1 *}$, Wei $\mathrm{Fu}^{2}$, and Hechao Zang ${ }^{1}$ \\ ${ }^{1}$ Shandong Provincial Key Laboratory of Ocean Environmental Monitoring Technology, Institute of \\ Oceanographic Instrumentation, Shandong Academy of Sciences, Qingdao 266001, China \\ ${ }^{2}$ Navy Qingdao First Sanatorium, Qingdao 266001, China
}

\begin{abstract}
Through foaming experiment of Zhongtai AH-70 asphalt, the best foaming temperature water consumption and influence factors of foamed asphalt's foaming features are determined; By designing the proportion of foamed asphalt cold in-place recycled mixture combined with the water stability experiment, for this mixture the best foamed asphalt addition is $3 \%$, and proportion of the mixture is RAP: fine aggregate: cement=75:23:2. Using SEM technology, the mechanism of increasing on the intensity of foamed asphalt mixture resulted by the addition of cement was analysed. This research provides reference for cement admixture's formulation in the designing of foamed asphalt cold in-place recycled mixture.
\end{abstract}

\section{Introduction}

In China, the total length of the national road was 469.63 million kilometres by the end of 2016. So there will be a large amount of recycled asphalt mixture in the road pavement renovation, renovation and conservation every year. If calculating by $12 \%$ of highway pavement need repair, there will be 2.2 million tons recycled asphalt mixture every year ${ }^{[1]}$. Asphalt cold recycling can be a good solution, which can make the old pavement materials reused and save $40 \%-50 \%$ of the total investment ${ }^{[2]}$. Foamed asphalt is the bituminous material that contains a large amount of evenly dispersed bubbles after expansion. In a special foaming device, the expansion occurs when the heat asphalt comes into contact with the water. Now, foamed asphalt is used as a regenerative agent for recycled RAP. When foamed asphalt comes into contact with the aggregate, it suddenly becomes millions of tiny particles and spreads on the surface of the fine aggregate especially particle size less than $0.075 \mathrm{~mm}$. This kind of the fine aggregate with foamed asphalt can be filled in the gap between the coarse aggregate and after mixing and compacting, the asphalt rubber paste is formed that makes the mixture a certain cohesion and strength ${ }^{[3,4]}$. In recent years, the cold regeneration technique of recycled waste road materials by foamed asphalt has been famous for its remarkable advantages in energy saving, environmental protection and economy ${ }^{[5,6,7]}$. Before using foamed asphalt cold regeneration technique to renovate road pavement, the proportion of mixture should be designed by laboratory research. Through foaming

*Corresponding author: caike0501@163.com 
experiment of Zhongtai AH-70 asphalt, the best foaming temperature, water consumption and influence factors of foamed asphalt's foaming features are determined; By designing the proportion of foamed asphalt cold in-place recycled mixture combined with the water stability experiment, for this mixture the best foamed asphalt addition cement addition and proportion are determined.

\section{Experiment}

\subsection{Raw materials}

Foamed asphalt is Zhongtai AH-70 asphalt. Table 1 is the technical indicators of Zhongtai AH-70 asphalt. The recycled asphalt pavement (RAP) is from highway milling material in Wuhan, China. Fig. 1 is the particle size distribution of stabilized soil and RAP. Stone dust is $0 \sim 3 \mathrm{~mm}$ limestone. The mine powder is limestone powder. Cement is P.O. 425 ordinary Portland cement from Huaxin cement factory, table 2 is its chemical composition. Water is just general water.

Table 1. Technical indicators of Zhongtai AH-70 asphalt.

\begin{tabular}{|c|c|c|}
\hline Technical indicators & Test results & Specification requirements \\
\hline Penetration $\left(25^{\circ} \mathrm{C}, 100 \mathrm{~g}, 5 \mathrm{~s}\right) / 0.1 \mathrm{~mm}$ & 65 & $60 \sim 80$ \\
\hline Ductility $\left(5 \mathrm{~cm} / \mathrm{min}, 15^{\circ} \mathrm{C}\right) / \mathrm{cm}$ & $>100$ & $>100$ \\
\hline Softening point (ball and ring method $) /{ }^{\circ} \mathrm{C}$ & 48 & $>47$ \\
\hline
\end{tabular}

Table 2. Chemical composition of cement.

\begin{tabular}{|c|c|c|c|c|c|c|c|c|}
\hline Chemical composition & $\mathrm{SiO}_{2}$ & $\mathrm{Al}_{2} \mathrm{O}_{3}$ & $\mathrm{Fe}_{2} \mathrm{O}_{3}$ & $\mathrm{CaO}$ & $\mathrm{MgO}$ & $\mathrm{Na}_{2} \mathrm{O}$ & $\mathrm{SO}_{3}$ & $\begin{array}{c}\text { Ignition } \\
\text { loss }\end{array}$ \\
\hline Content $/ \%$ & 21.73 & 4.25 & 2.67 & 63.59 & 2.21 & 0.55 & 2.39 & 1.75 \\
\hline
\end{tabular}

\subsection{Preparation of foamed asphalt}

Foaming experiment of Zhongtai AH-70 asphalt choosing $150{ }^{\circ} \mathrm{C}, 160{ }^{\circ} \mathrm{C}$ and $170{ }^{\circ} \mathrm{C}$ three kinds of foaming temperature, the water consumption at each temperature was $1.5 \%, 2.0 \%$, $2.5 \%$ and $3 \%$ respectively. The water consumption used is based on asphalt content. Every experiment were done three times, take the average result to measure foamed asphalt's expansion ratio and half-life.

\subsection{Specimen preparation and test methods}

By comparing the particle size distribution of RAP with engineering design level gradation of foamed asphalt cold in-place recycled mixture, the mixture gradation is determined. Foamed asphalt cold in-place recycled mixtures have five different cement compositions of $0 \%, 1 \%, 1.5 \%, 2 \%, 3 \%$. The optimized amount of water used and the maximum dry density were determined by the compaction test, and the mixing water consumption is calculated. The impaction test was referring to the method in Highway Engineering stable inorganic binder materials testing procedures (JTG E 51-2009) the preparation of mixture standard 
Marshall Specimens was refer to the methods in Road engineering asphalt and asphalt mixture test procedure (JTG 052-2000).

After demoulding, specimens kept in $40{ }^{\circ} \mathrm{C}$ ventilation oven by $72 \mathrm{~h}$ curing. This curing method can simulate the condition after $10 \mathrm{~d}$ actual pavement construction ${ }^{[8]}$. Splitting test: Specimens at $20^{\circ} \mathrm{C}$ environment after $1.5 \mathrm{~h}$ do dry splitting test; Specimens at $20{ }^{\circ} \mathrm{C}$ water flooding after $24 \mathrm{~h}$ do wet splitting test. Using digital imaging microscope and SEM technology, we analysed the mechanism of increasing on the intensity of foamed asphalt mixture resulted by the addition of cement.

\section{Results and discussions}

\subsection{Features of foamed asphalt}

Fig. 1 is characteristic curve of foamed asphalt at three different temperatures. It is shown that at the same temperature, the foamed asphalt's half-life decreases with the increase of water consumption. The half-life decreases rapidly, when water consumption increases from $1.5 \%$ to $2.5 \%$. But, from $2.5 \%$ to $3 \%$, the half-life reduction is significantly smaller. The expansion ratio increases with the water consumption, and the increase is more uniform. Zhongtai AH-70 asphalt best foaming temperature is $160{ }^{\circ} \mathrm{C}$ and water consumption is $2 \%$, and the expansion ratio is 11 times and the half-life is $10 \mathrm{~s}$.

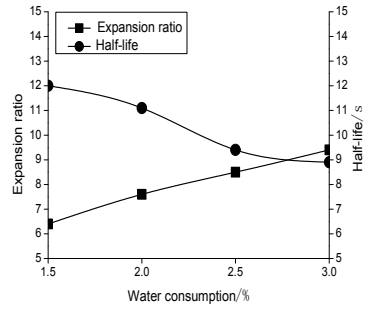

(a) $150^{\circ} \mathrm{C}$

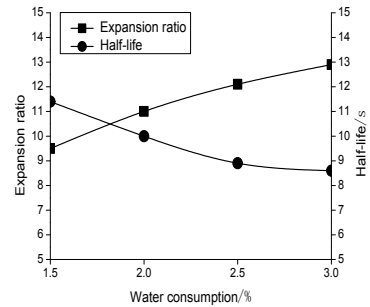

(b) $160{ }^{\circ} \mathrm{C}$

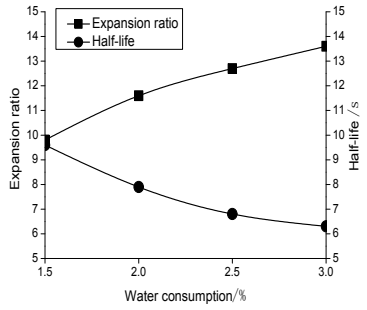

(c) $170^{\circ} \mathrm{C}$

Fig. 1. Characteristic curve of foamed asphalt at three different temperatures.

\subsection{Design for proportion of cement-foamed asphalt cold recycled mixture}

Table 3. RAP screening results and standard graduation

\begin{tabular}{|c|c|c|c|c|c|c|c|c|c|c|c|c|}
\hline \multirow{2}{*}{ Graduation } & \multicolumn{10}{|c|}{ Through rate of different sieve pore } & \multicolumn{10}{|c|}{ (19.5 } & 26.5 & 16 & 13.2 & 9.5 & 4.75 & 2.36 & 1.18 & 0.6 & 0.3 & 0.15 & 0.075 \\
\hline RAP/\% & 100 & 98.9 & 95.7 & 84.9 & 65 & 48.7 & 34.4 & 24.0 & 13.3 & 3.11 & 0.92 & 0.24 \\
\hline $\begin{array}{c}\text { Upper } \\
\text { limit/\% }\end{array}$ & 100 & 100 & - & - & 85 & 65 & 55 & - & - & 30 & - & 20 \\
\hline $\begin{array}{c}\text { Lower } \\
\text { limit/\% }\end{array}$ & 100 & 90 & - & - & 60 & 35 & 30 & - & - & 10 & - & 6 \\
\hline
\end{tabular}

Table 3 is RAP screening results and standard graduation. It is shown that the RAP's through rate of $0.3 \mathrm{~mm} \sim 0.075 \mathrm{~mm}$ sieve pore are far below the standard. Fine aggregate is less than standard, especially the through rate of $0.075 \mathrm{~mm}$ sieve pore is $0.24 \%$ that far from the $6 \% \sim 20 \%$ requirement in the standard. So proportion of the mixture is $75 \% \mathrm{RAP}+25 \%$ fine aggregate. Fig. 2 is screening result of mixture that meets the requirement of standard graduation. Table 4 is the result of mixture's compaction test and mixing water 
consumption. Mixing water consumption based on the empirical formula of the Witgen cold regenerative technology manual: $\mathrm{W}_{\text {add }}=1+\left(0.5 \mathrm{~W}_{\text {omc }}-\mathrm{W}_{\text {air-dry }}\right)$. Wadd is mixing water consumption, $\mathrm{W}_{\text {omc }}$ is optimum moisture content and $\mathrm{W}_{\text {air-dry }}$ is maximum dry density.

Table 4. The result of mixture's compaction test

\begin{tabular}{|c|c|c|c|}
\hline Cement content $/ \%$ & $\mathrm{~W}_{\text {omc }} / \%$ & $\mathrm{~W}_{\text {air-dry }} / \%$ & $\mathrm{~W}_{\text {add }} / \%$ \\
\hline 0 & 5.92 & 2.212 & 3.96 \\
\hline 1 & 6.13 & 2.229 & 4.05 \\
\hline 1.5 & 6.22 & 2.236 & 4.10 \\
\hline 2 & 6.31 & 2.243 & 4.13 \\
\hline 3 & 6.49 & 2.256 & 4.21 \\
\hline
\end{tabular}

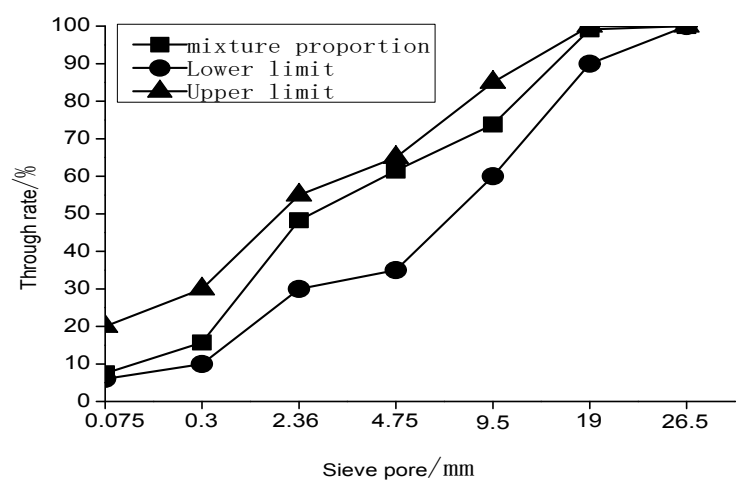

Fig. 2. Screening result of mixture.

\subsection{The water stability of different cement content foamed asphalt mixtures}

Fig. 3 is different cement content and foamed asphalt content mixture's splitting strength and Fig. 4 is wet splitting strength of the mixture. As shown in the Fig.s, the splitting strength of the mixture was increased significantly with the increase of the cement content, but the increase was gradually decreased. At the same cement content, there is the optimum foamed asphalt content. Under the condition of $2 \%$ cement content and 3\% foamed asphalt content, splitting strength is $0.512 \mathrm{MPa}$ and wet splitting strength is $0.416 \mathrm{MPa}$ and dry and wet splitting strength ratio is $81.2 \%$. It fully meets the standard requirement that the dry splitting strength is less than $0.4 \mathrm{MPa}$ and the ratio is less than $75 \%$. Therefore, for this mixture the best foamed asphalt addition is $3 \%$, and proportion of the mixture is RAP: fine aggregate: cement $=75: 23: 2$ 


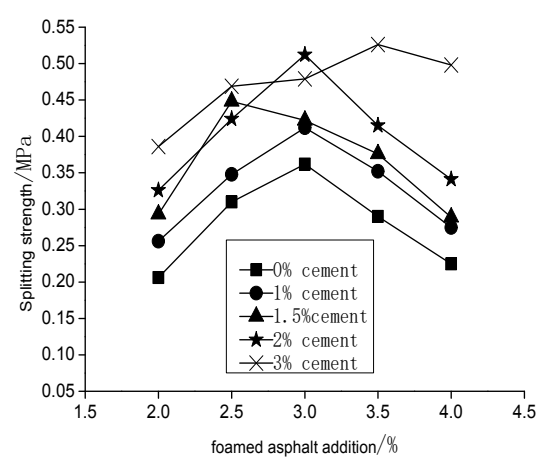

Fig. 3. Splitting strength of the mixtures.

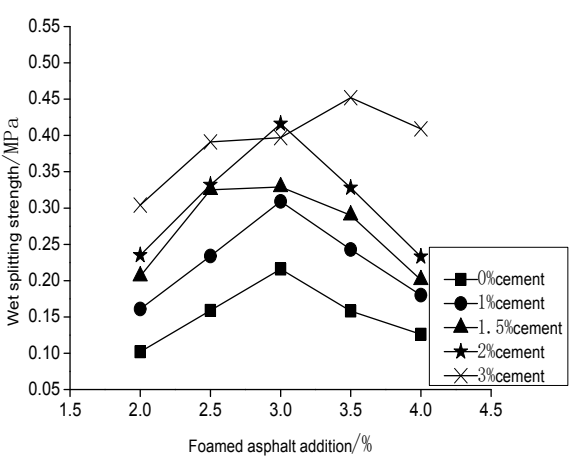

Fig. 4. Wet splitting strength of the mixtures.

After the hydration of the cement in cold cycling mixture, hydration products develop to the surrounding space of the cement particles, criss-cross, and gradually fill the mix of all the capillary space. Thereby it forms a uniform, dense; pore closed the whole structure, and enhances the overall strength of the mixture of water and anti-damaging ${ }^{[9]}$. It is clear that acicular and fibrous gels are interwoven overlapping to form a network structure in Fig. 5 . Thus, the cement hydration products contained in the foamed asphalt mixture hydrolysed into space mesh structure and wrapped up the aggregate particle. It is the main reason that the cement can enhance the mixture's intensity as well as the water stability. The amount of cement is not the higher the better. The mixture of high cement adding is easy to produce severe shrinkage cracks and it leads to lower strength.

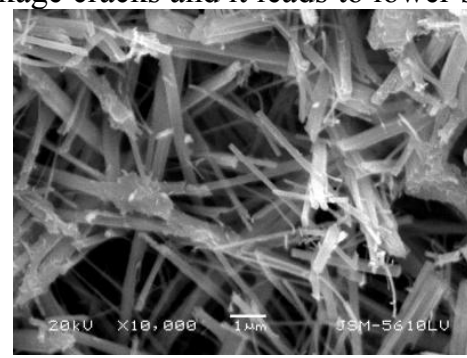

(a) Acicular gels

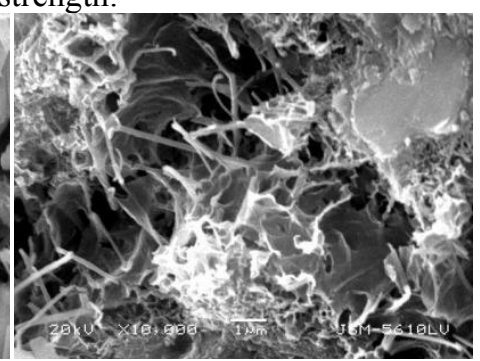

(b) Fibrous gels

Fig. 5. SEM images for hydration products of the mixture

\section{Conclusions}

At the same temperature, the foamed asphalt' $s$ half-life decreases with the increase of water consumption, but the expansion ratio increases with the water consumption. Zhongtai $\mathrm{AH}-70$ asphalt best foaming temperature is $160{ }^{\circ} \mathrm{C}$ and water consumption is $2 \%$, and the expansion ratio is 11 times and the half-life is 10s. The splitting strength of the mixture was increased significantly with the increase of the cement content. At the same cement content, there is the optimum foamed asphalt content. For this mixture the best foamed asphalt addition is 3\%, and proportion of the mixture is RAP: fine aggregate: cement=75:23:2. 
This work was financially supported by National Key Research and Development Program (2016YFC1400802) and Provincial key Research and Development Program (2016GGH4501).

\section{References}

1. G.K. Wang, Z.L.Zhou. Foamed Asphalt Cold in-plant Recycling Applied in Pavement, Reconstruction Transport Standardization, 219 (2010),p.112-117

2. Guidelines for Cold In-Place Recycling[M]. Asphalt Recycling and Reclaiming Association, Annapolis, MD, 1991.

3. L.Y. Wei, Z.W. Liu, H.R Zhang, J. Wang. Experimental Analyse of Foamed Asphalt Stabilization Cold-recycled Mixture in Old Asphalt Pavement, Journal of Hebei University of Technology. 37(2008), p.100-104

4. C.X Cao, G.P. He, C.R. Sun. The Cold Regeneration Technique by foamed asphalt, Highway, 11 (2003), p.99-101

5. Z.K. Xu. Effect of Foam Asphalt and Cement Content on Road Performance of Cold Recycled Asphalt Mixture, Highway Engineering, 42 (2017), p.245

6. T.Q. Ling, L. He, Y. Ma. A Cold Recycling Technique for Foamed Bitumen Mix, Journal of Civil Architectural \& Environmental Engineering, 31 (2009), p.141-145

7. F.Z. Shi, X.J. Li, D.Q. Sun, W.M. Lv. Discussion about Design Methods for Recycling Cold Mix Asphalt [J].Highway, 11 (2004), p.103-107.

8. X.J. Li. Guide Experimental Study on Shearing Properties of Cold-Recycled Mixtures Using Foamed Asphalt, Journal of Building Materials,13(2010), p.27

9. X.B. Yin. Performance of Emulsified Asphalt Full Thickness Cold Recycling Subgrade Materials, Advanced Materials Research, 915-916 (2014),p. 704 